CHAPTER 19

\title{
Empowerment, Resilience, and Stewardship as Learning Outcomes
}

\author{
Recalibrating Education to Nurture a New Generation of Climate Activists
}

William Bertolotti

\begin{abstract}
For the teaching profession, 2020 has become an inflection point, with profound disruptions serving as opportunities to redefine teaching philosophies and pedagogies. In this chapter, I share the mindsets and practices that have helped me as a high school teacher nurture emotional resilience, academic growth, and civic responsibility, and I identify tactics that fellow educators can use to empower students for success in an uncertain future, including a sense of ownership over their community, a feeling of stewardship toward the global environment, and the drive to connect and partner with experts.
\end{abstract}

\section{Keywords}

21st century education - teaching pedagogy - environmental science - student activism - empowerment - climate change

Teaching is kindling the spark, stirring the insatiable hunger, and lighting the communal fire. Approaching my twelfth year of teaching high school social science research, I am grateful for the opportunity to share my perspective as an educator, mentor, and advocate. We adult role models have so little time in which to fulfill our responsibilities for the next generation, so quickly do they grow up. We spark aspirations, accelerate ambitions, nurture identities, and prepare young adults for productive and meaningful lives in an uncertain future. I aim to share with you some tools that helped me nurture in students a hunger for exploration and a love and respect for the transience of life. Through patience and compassion, we can instill in the next generation

(C) UNESCO IBE, 2021 | DOI: 10.1163/9789004471818_020

This is an open access chapter distributed under the terms of the CC BY 4.0 License.

William Bertolotti - 9789004471818 
a sense of ownership over their community, a feeling of stewardship toward the global environment, and the drive to connect and partner with experts. The purpose of this chapter is to share a philosophy and mission statement for teaching that empowers students with the skill sets necessary for a tumultuous new decade, and to articulate an experience-based roadmap for educational practice, reproducibility, and sustainability.

Throughout, I will provide examples of past efforts of students and the mindsets I instilled to guide their work. My hope is that if you have decades' more experience than me, you will use this reading as an opportunity to reflect on your successes and your opportunities for maintaining your passion and commitment. If you are just beginning your journey as an educator, to know that some of my ideas were of use would warm my heart. For all of us, clarifying our commitment to students and maintaining an open mind as to the strategies that will accelerate their growth - these are the attributes of the teacher whose students gain the foundation for a truly meaningful high school experience.

The chapter begins with climate preparedness, potentially the fundamental danger that underlies all emerging risks in the 21st century. Whereas nuclear war represented potential doom in the 2oth century, today climate change, with its disruptions of food security, increase in storms of record-setting devastation, and rising likelihood of disease, is our sword of Damocles. This challenge, global in scope, requires the energy of an entire generation, and if the UN General Assembly president was correct and our window for preventing the worst effects of climate change closes in 2030, we cannot wait until our students are in college for them to get spurred into action. Our students are the stakeholders of a world that may not be hospitable. We must engage them now, motivate them now, and empower them with the necessary skills now. In the following section, I share mindsets that promote such student empowerment.

\section{Seeing Student Empowerment as the Pathway to Promoting Climate Awareness and Activism}

For any teacher seeking ideas to augment the learning environment, be it through a program or project, the questions that follow are worthy of consideration.

\subsection{How Can I Nurture the Talents of My Students?}

We educators spend a significant amount of time working with developing human beings, and part of the joy of teaching is just spotting the aptitudes and interests of our students. This approach is a way into the nurturing of the 
talents of your students. Incorporate into your lessons opportunities for students to leverage creative skills outside the formal curriculum, be they coding, the arts, or communication. When you observe that a student demonstrates a specific strength in a skill, or a pronounced interest in learning a skill, consider: Do I know experts in the field? How can I work with my student to connect them with an expert?

Integrate the individual talents of students into a class product. For example, research into the carbon footprint of the local community can culminate in a diverse outreach effort, including targeted outreach by extroverted students to local government leaders, or video advertisements exploring methods of persuasion through effective visual and language cues aimed to change community behaviors. In this type of classroom, each child contributes meaningfully to a greater outcome and each child explores beyond their comfort zone in a collaborative setting.

\subsection{How Can I Promote Student Empowerment?}

A significant challenge I experienced as a teacher was trying to fit my profession into a preconceived notion of top-down education. The paradigm I initially worked from included having to be an expert in all things, being in control, and directing my students toward whichever outcomes I as a professional identified. It was authoritarian. Reflecting upon my interactions with students, I realized that I was forcing myself to establish benchmarks of growth for my students, implicitly demanding that students conform to my own professional vision of productivity and accomplishment. In hindsight, this form of growth by fiat may have stifled students, teaching them that their own development was governed by an extrinsic force.

Over several years, I worked to redefine my traditional preconceptions of student work by serving as a guide to student-led problem-solving. I found new ways to promote student empowerment. Now when students ask me for information, my response is, "Beyond me, who could you ask?" I teach students how to search online for experts in the field (one trick is googling "[topic] research faculty site: .edu". Once students identify experts in the field, my next goal is to coach students in making their first connection by composing a business outreach letter, planning the content, pacing, and delivery of a first phone or Zoom call, and maintaining communication with contacts. Teaching is coaching students through accomplishments that promote ownership, learning, and the acquisition of essential work skills.

"I can" is the central mindset I instill in my students. My students learn that "I can" contact experts in the field. Investing in, and nurturing, students' sense of self-worth is critical, and I stress to students that they are worth the time 
of these experts. Working with the students to send their first query, exposes them to their anxieties, and teaching them how to communicate with experts helps them confront their anxieties in a productive way. Even when contacts are sparse, I urge my students to continue sending out letters. We troubleshoot for reasons that might explain insufficient responses, be they the letter, be they the contacts we are targeting. Every experience of "failure" is reframed as an opportunity for students to reevaluate their strategies and identify the most effective methods for reaching their goals. Ultimately, when a response arrives, students realize that they can connect, and this increases the likelihood of further outreach. The student who hesitated at writing a letter or making a teleconference call becomes the student connecting with researchers, government officials, and business leaders, the young adult with the confidence to build connections and demand change.

My last point about empowerment is that it is crucial that educators shape students into informed citizens. We need to teach students how to challenge accepted truisms using rigorous analysis. From research and data collection to statistics testing, students are capable of working with data and developing their own conclusions. For example, students collected home prices from a residential website and compared home values between towns of differing demographic composition. The students learned how to run and interpret ANOVA tests using a statistical package and found that indeed, residential disparities were significant. I challenged their conclusions, forcing them to defend their work, methods, and assertions. Students had to demonstrate beyond a reasonable doubt that their work was sound. This experience helped them develop their ability to advocate - for themselves - and later, when students designed solutions and interventions - for their community. This type of project can be adapted for students studying the impact of global climate change. Students can examine the socioeconomics of communities most at risk of harm from rising sea levels. Students can examine which communities are likely to experience extreme heat or calculate how losing farmland to desertification may affect global food security. One incredible asset that contemporary students possess is the sheer volume of data accessible from the convenience of a browser. Teachers can guide students to become fact-wielding storytellers, data-literate reporters, and compelling global advocates.

One student-led project on microplastics combined science research with environmental activism. The student wanted to document the prevalence of microplastics pollution in the food chain. He collected sand crabs from a local beach to isolate microplastics particles from the gut tract. The student's initial survey revealed over 200 plastic particles in the creatures, and, relying on his general observation of plastic litter washing onto the beach, he connected with the town government to share the results and push for change. Among 
my most rewarding experiences in this instance was seeing this student take ownership of the project and gain a determination to connect with local leaders to brainstorm strategies for decreasing the use of plastic utensils and straws in restaurants.

Meaningful experiences like these can be reproduced in any classroom. Students can conduct surveys, perhaps even treating the opportunity like a data scavenger hunt. Have them collect data and research the reasons underlying what they find. Teach them how to use graphs, tables, and figures to create an honest and compelling narrative. Then challenge them to answer the "What next?" and "So what do we do about it?" questions. We can channel students' innate curiosity and restlessness into meaningful activity, while building their identification with the sciences and building up stronger connections with the community.

\subsection{How Can I Redefine the Notion of Control?}

With regard to considering how to define the notion of control, note the recurring theme: the teacher is not the arbiter of a student's educational experience. Instead, a teacher should approach learning as if it were a conversation. After clearly establishing the general parameters of a task, give students the space and time to approach a preliminary benchmark. In this approach, space means the students' knowing that the teacher will neither micromanage them nor provide unsolicited input; and time means that room is allowed for the creative process that students follow. When students share their work, frame the experience as a presentation of a rough draft, a work in progress. Students share their products and the challenges they encountered. As a teacher, emphasize less the outcome (successes and failures) and more the process adopted by the student. Consistently ask for the procedure the student used. Have them articulate the method they used, its steps, and any failures they experienced. These failures are an educational windfall. Have students autopsy these moments. They can reflect on their strategy and actions. Have the students pose alternate approaches and guide them with alternatives where necessary. Stress to the student that failures are valuable opportunities for exploring alternate approaches, that failures shaped the growth of very successful people who used these experiences as lessons for real learning.

To work with students through failure is to embrace key emotional and character components of education. I would have to sympathize with anyone who feels that education as a system prizes compliance. As a growing teacher, I caught myself echoing the standard tropes of a frustrated teacher: "There's no time for questions; we have to complete the curriculum". "You didn't follow the rubric". "How dare you show disrespect?" Under the mistaken idea of 
education as a service for conveying information, I had trapped myself in a mindset that turned students into commodities of knowledge retention.

I subsequently realized that uncertainty and frustration had been framed in a negative light, as reactions that are unproductive. What if, instead, these feelings were acknowledged as meaningful and important facets of growing? Perhaps a key lesson should be that anger spurs efforts for change, that frustration reflects a dissatisfaction with how things are and promotes a search for a better approach. Perhaps, then, teachers can guide students toward mastering these powerful feelings and leveraging them as forces of growth. Perhaps, then, anger can be used to explore methods for combating injustice and ignorance, as frustration allows for the escape from old mindsets. Leveraged together, anger and frustration are, in fact, tools our students can use to change themselves and society.

\subsection{How Can I Nurture Compassion as a Force for Change?}

With any lesson plan, the teaching profession identifies a basic prerequisite. In the case under discussion, it's compassion. Keeping in mind that our responsibility centers around working with human beings of great potential, we serve as guides and mentors. We help them discover their interests. We stoke their passion, challenge their instincts and preconceptions, and counsel them through failure. Choosing the role of educator, teachers must acknowledge that their principal responsibility is to raise a future citizen, to prepare each child for a meaningful and productive life.

Further, compassion should also be nurtured in our students because it is the underlying mindset that fuels any motivation and willingness to address the dire challenges of the current climate crisis. Students need compassion for the environment and for the thousands of living species on the verge of extinction; compassion for the millions of human beings suffering the effects of ever-rising global temperatures and sea levels; and compassion toward the self - namely, the determination that neither I, nor my neighbor, nor my future descendants will experience the catastrophic consequences of climate change, a sense that we all deserve to live our time in a healthy and safe world. Compassion drives our students toward action and toward justice, and we as teachers would do well to emulate compassion and instill this mindset into the next generation of student leaders.

Contemporary science extends beyond a single lens of discovery, with experts across divers disciplines contributing to research. Experts in biology and 
chemistry routinely work with programmers. Educators can craft learning experiences that leverage the individual attributes and skills of their students. It is now possible to imagine a learning environment in which the class collaborates on a learning experience. The budding data analysts can learn and apply descriptive and inferential statistical testing while other students design methodologies and execute workflows. Meanwhile, students can practice effective communication, crafting compelling narratives, as other students practice connecting with experts and policy drivers to enact change.

This experience-based student collaboration is an opportunity to teach students how to plan like scientists. Imagine teaching a class on environmental science in which students engage in the following pipeline of learning.

\subsection{Identifying Challenges}

In the phase of identifying challenges, students spend time brainstorming environmental problems relevant to their community. Learning how to use digital platforms like Google Forms or Survey Monkey, students design a survey for their families and neighbors, asking their feedback on relevant environmental problems. Practicing this community outreach, students can simultaneously learn best practices for survey design and connecting with their community. Analyzing the results, students reach a consensus on which challenge they will address.

\subsection{Designing Solutions}

In the next step, designing solutions, students research the full scope of their identified problem. For example, students following up on community concerns about high summer temperatures may begin researching causes of, and solutions to, the urban heat-island effect. Students write to scientists, contact local experts, and as they establish momentum, conduct research on their own terms, networking with experts in the field. This phase involves a sustained learning experience that incorporates both hard and soft skills of research science.

\subsection{Testing and Adapting Models}

Once the students come across a variety of solutions, from green roofs to solar energy, they test and adapt the models they have come up with. Have the students research the viability of these possible solutions. Better yet, have the students survey the community again for input, reinforcing their connection to the community. Connecting again with scientists, students can design models and action plans, even build their own prototypes and test them using metrics gleaned from their previous research. Previous efforts fuel current progress while providing future direction. 
As a teacher, among our many core responsibilities is that of facilitating the integration of our students into the greater society. Each short year is an investment, as teachers work to ensure that communities gain confident, informed, and passionate citizens. In furtherance of that end, my goal as a teacher was ensuring that my students' growth occurred in the context of helping their community. Furthermore, students are inundated with news that scientists are unvalued and that climate concerns are secondary to immediate comforts and profits. These signals threaten children's sense of control. Teaching students to engage in citizen science is valuable in that it reestablishes that sense of control, showing students that by learning about the world, persevering in the research process, and translating findings to community level outcomes, they can become agents of change.

As a research teacher, I challenged my students to apply their research findings to designing a community impact project. Projects directed toward the community provide students with opportunities to connect with organizations outside the school that have the mission and expertise to accelerate professional growth. This year, I was fortunate to collaborate with the Eco Ambassadors program hosted by the Columbia University Center for Sustainable Development, and this collaboration accelerated the development of two student projects.

\subsection{Embracing Eco Ambassador Projects}

The first project involved a student who completed a research project surveying microplastics at a local beach. The Eco Ambassadors Program became this student's symposium, providing a forum for sharing findings to students across the globe. By sharing results, this student became an educator in their own right, guiding other students in developing their own research projects. Furthermore, the student learned how to connect with community leaders to propose programs for limiting plastics pollution.

Two other students were interested in the role of green engineering in decreasing energy usage and its resulting carbon emissions. These students constructed two structures, one with a traditional tarpaper roof and one with a green roof, with the goal of calculating temperature and resulting cooling costs (in both financial and carbon-emissions terms). The program allowed these students to share their approach with experts and convey it to students in other countries, providing other students with the concrete methodology to reproduce their study. Using this forum, the students practiced articulating persuasively the rationale of the study and sharing clearly their project methods. 
When the students complete their project, they will work to push for the integration of green architecture into their schools and the greater community. As a teacher, connecting your students with programs, be they at the university level, connected to governments, or with not-for-profits, will provide your students with resources, expertise, and an environment in which they can practice bringing about change.

\subsection{Using the United Nations Sustainable Development Goals}

The United Nations organized the most significant global challenges into 17 Sustainable Development Goals (SDGs), clearly presented on a central hub that anyone can access. I recommend that teachers manage to connect every learning experience with these SDGs, be it by showing how course content reflects an SDG or by directly challenging students to design projects that address the 17 goals. Directing students to meet these sustainability goals creates a learning experience in which students realize that their efforts can have real-world application and that their current work serves as practice for bringing change to their community.

As an example, students can design rhizofiltration floating islands to turn fertilizer runoff into nourishing crops - thus learning how a single project can serve as a multi-faceted solution for the environment, through promoting food security (Goal 2) and protecting marine environments from algal blooms (Goal 14). Another lesson can focus on how singular efforts benefit from a multidisciplinary collaboration. In this example, a class can explore filtration technology as a key to affordable clean water systems (Goal 6). Some students can examine the economics and market forces entailed in producing such a system. Other students can study the logistics necessary for establishing a stable supply chain from factory to community. Other students can focus on improved material engineering that would permit the production of more effective and cheaper filters. Integrating the SDGs into your curriculum will promote the link between science and society, teaching students that scientists play a critical role in meeting community and global challenges.

For any teacher looking for a starting point, a web search for "170 Daily Actions UNSDG" will take you to a UN document that provides 10 daily activities addressing each of the 17 goals. Applicable to any level of teaching, this document can guide secondary level research projects or short activities at the elementary level. For example, Goal 5 (gender equality) can be addressed by high school students conducting background research and designing data collection methods on the current state of balance between work and life in company culture. Simultaneously, a fifth-grade classroom could role-play equalizing household responsibilities and decision making. As a guide, the UN SDGs reinforce the importance of teaching skills rather than focusing solely 
on information, and with a large number of suggested actions, teachers can integrate the SDGs into the learning environment, transforming the classroom into a living lab for empowerment and future activism.

\subsection{Fostering Data Literacy}

One final mindset that teachers should promote in students: their responsibilities in the production and consumption of information. Current upheavals in United States society are further inflamed by the mass distribution of misinformation, which by its nature distorts reality and corrupts the public trust. Working with students, we must teach them how to process information and how to maintain a skeptical mindset. Remind them that even though a source may state what they perceive to be truth, the reality is that, indeed, this truth is solely a perception. Have students practice analyzing the evidence provided by sources. Have them identify potential limitations, be they sources of bias, or weak "effect sizes", as they say in statistics. Give students the results from a paper and challenge them to deduce the original methodology and then design a future study. Familiarize them with working with statistics and train them to know when statistics lie. I highly recommend that teachers start students with the subsequently retracted 1998 Lancet report on the measles vaccine (see https://briandeer.com/mmr/lancet-paper.htm). Have students develop criteria for reliability and then assess the report based on their criteria. Show them how one failure in research can undo decades of progress toward defeating an illness. In the era of Covid-19, when conspiracy and misinformation feed a significant distrust and disregard for epidemiological expertise and basic protocols for public safety, students must be shown the incredibly high stakes involved in neglecting responsible science.

\section{In Closing}

For many of my students, this year has served as a cruel lesson and a harbinger of challenges to come. This decade promises ever-strengthening passions for change and global justice, more frequent environmental and civic disruptions, and the ever-present global risks of illness and climate change. Our time for molding the next generation of global citizens is short, limited to the high school years we have with them, and the ramifications of the experiences we provide them are lifelong. I hope that we as educators will continue investing in our students, empowering them with the scientific skills, skepticism, and resilience necessary for stability in this age of anxiety. Nonetheless, this work is intended as a document of hope, an opportunity to acknowledge our chance 
to engineer an infrastructure of change through empowerment for the future. Our children are not the vulnerable victims of an inevitable and difficult future. Instead, they deserve to be our leaders, our agents of change, and our wardens of the world. Even now, when our students are confronted with so many dire and starkly brutal signs of the ills of the world, they endure, they persevere, they protest, they grow rapidly into adulthood. As teachers, few things are as heartwarming and inspiring as the raw power inherent in each student - a potential waiting to be honed - and a reminder that in every student's ability to succeed resides also our affirmative duty as educators to continue nurturing humanity's greatest potential. May the successful advocacy and stewardship of the next generation be our greatest legacy. 
William Bertolotti - 9789004471818

Downloaded from Brill.com04/26/2023 06:41:41AM via free access 